\title{
Journal of Transportation and Logistics
}

\author{
$1(1), 2016$
}

\section{Çok Kriterli Karar Verme Yöntemlerinden AHP TOPSIS ve PROMETHEE Karşılaştırılması:}

\author{
Gemi Inşada Ana Makine Seçimi Uygulaması \\ Sümeyra Uzun| İstanbul University, Faculty of Economics, sumeyrauzun@istanbul.edu.tr \\ Halim Kazan | İstanbul University, Faculty of Economics, halim.kazan@istanbul.edu.tr
}

\section{Öz}

Anahtar Sözcükler:

Karar Verme,

AHP,

TOPSIS,

PROMETHEE.
Karar verme karşılaşılan durumlar karşısında en uygun tepkinin verilmesidir. Fakat karşılaşılan problem belli bir amaç doğrultusunda belli ölçütlere göre birden fazla alternatif arasından olabilir. Böyle bir karar problemi karşısında çok ölçütlü karar verme yöntemlerine başvurmak en uygun çözüme ulaşmayı sağlamaktadır. Çalışmada karar verme ile ilgili bilgi verildikten sonra çok kriterli karar verme yöntemleri olan AHP, TOPSIS ve PROMETHEE yöntemleri ele alınmıştır. Ele alınan bu yöntemler gemi inşada önemli olan ana makine seçimine uygulanmıştır ve bulunan sonuçlar karşılaştırılmıştır. Bu yöntemlerin uygulanmasındaki amaç projeye en uygun makinenin seçilmesidir. Bu çalışmada NB 25 Wartsila balıkçı gemisi projesine uygun ana makine seçimi problemi ele alınmıştır. Toplam 12 kriter belirlenmiş ve bu kriterlere göre 7 ana makine arasından projeye en uygun makineye karar verilmeye çalışılmıştır. Karar problemine AHP, TOPSIS ve PROMETHEE yöntemleriyle çözüm getirilmeye çalışılmış ve bulunan sonuçlar karşılaştırılmıştır. Yapılan uygulama sonucunda AHP ve PROMETHEE yöntemlerinin yakın sonuçlar verdiği gözlemlenmiştir. Ana makine için AHP ve PROMETHEE sonuçları gerçek durumla tutarlılık göstermiştir.

\section{Comparing MCDM Methods of AHP, TOPSIS and PROMETHEE: A Study on the Selection of}

\section{Ship Main Engine System}

\section{ABSTRACT}

Keywords:

Decision Making,

AHP,

TOPSIS,

PROMETHEE.
Decision is optimum reaction in the face of situations, but encountered problems can be among more than one alternatives in accordance with precise purpose and according to certain criteria. Going for multiple criterion decision making methods fend us to reach optimum solutions in the case of facing decision problems. After informing regarding with studies, multiple criterion decision making methods were talked over (discussed) such as AHP, TOPSIS and PROMETHEE. Discussed methods were implemented to the selection of main engine which is important in the field of vessel building and results were compared. The purpose of implement these methods is to choose the most appropriate machine for the Project. The problem of choosing the most appropriate main engine was talked over on this study for fishing vessel NB25 Wartsila. Totally 12 criteria were ascertained and it was tried to choose the most appropriate main engine among 7 engines according to determined criteria. Decision problem was tried to solve with AHP, TOPSIS and PROMETHEE methods, and the results were compared. At the end of comparison, it was observed that AHP AND PROMETHEE methods gave us close results to each other. The results of AHP and PROMETHEE methods showed consistency in ( with) actual situation. 


\section{GiRiş}

İnsan, yaşamının her devresinde bazı problemlerle karşılaşır ve çözüm arayışına girer. Karşılaşılan problemler birçok alternatif arasında ve birden fazla kritere bağlı yapılmak istenmektedir. Bu durum ise karar vericiyi zorlu bir karar sürecine sokmaktadır. Karar verme sürecine geçmeden önce karar probleminin tanımına değinelim. Karar, bir durum karşısında verilen en uygun tepkidir. Karar verme ise kısaca birçok alternatif arasından en uygun olanı seçmektir. Bu çalışmada ele alınan karar verme ise birçok alternatif arasından belli kriterlere veya ölçütlere göre belirlenen amaç doğrultusunda en uygun alternatifin seçilmesi işlemidir.Bu çalışma gemi inşa sürecinde ana makine seçimi amacı doğrultusunda belli modeller arasında belli kriterlere uygun olarak AHP, TOPSIS, PROMETHEE yöntemleri ile seçim işleminin yapılıp en uygun modelin seçilmesi işlemini içerecektir. Ayrıca bu çalışmada farklı yöntemlerle elde edilen durumlar karşılaştırılıp yöntemlerin karar verme sürecine nasıl katkı sağladığı ve kendi arasında ne kadar tutarlı olduğu gözlemlenmeye çalışılacaktır. Ayrıca sektörde karar verme süreçlerinde çoklu karar verme tekniklerinin önemini araştırmak isteyen araştırmacı ve yöneticilere yardımcı olmak amaçlanmaktadır.

\section{Analitik Hiyerarşi Prosesi (AHP)}

Analitik hiyerarşi prosesi ilk olarak 1968 yılında Myers ve Alpert ikilisi tarafından ortaya atılmış ve 1977de ise Profesör Thomas Lorie Saaty tarafından bir model olarak geliştirilerek karar verme problemlerinin çözümünde kullanılır hale gelmesini sağlamıştır. (Yaralığlu,2001)AHP karar vericilerin karmaşık problemleri, problemin ana hedefi, kriterleri alt kriterler ve alternatifleri arasındaki ilişkiyi gösteren bir hiyerarşik yapıda modellemelerine olanak verir. AHP' nin en önemli özelliği karar vericinin hem objektif hem de sübjektif olarak karar sürecine dahil olabilmesidir. Yani AHP bilginin, deneyimin, bireyin düşüncelerinin ve önsezilerinin mantıksal bir şekilde birleştirildiği bir yöntemdir. (Kuruüzüm ve Atsan, 2001) AHP uygulamasına başlarken öncelikle hiyerarşi modeli kurulur. Analitik hiyerarşi prosesinde hiyerarşi kurulurken en üst basamakta problemin amacı yer alır. Alt basamakta ise problemle ilgili ana kriterler, ana kriterlerin bir alt basamağında ise ilgili kriterin alt kriterleri yer alır. Oluşturulan hiyerarşinin en alt basamağında ise problemle ilgili seçenekler bulunur. Karar probleminin hiyerarşi tablosu oluşturulduktan sonraki adım aynı önem derecesine sahip kriterlerin birbirine göre ağırlıkların belirlenmesidir. Bu aşamada birbirine göre ağırlıklandırma kısmında Saaty'nin 1-9 puanlı tercih ölçeğinden yararlanılır. Bu ölçeğin etkinliği farklı alanlarda yapılan uygulamalar ve başka ölçeklerle yapılan teorik karşılaştırmalar sonucunda saptanmıştır. (Kuruüzüm ve Atsan, 2001)

Tablo 1. 1-9 Puanlı Tercih Ölçeği

\begin{tabular}{|l|l|l|}
\hline Önem Derecesi & Tanım & Açıklama \\
\hline 1 & Eşit Derecede Önemli & Her iki faktör aynı öneme sahiptir. \\
\hline 3 & Orta Derecede Önemli & Bir faktör diğerine göre biraz daha önemlidir. \\
\hline 5 & Kuvvetli Derecede Önemli & Bir faktör diğerine göre kuvvetle daha önemlidir. \\
\hline 7 & Çok Kuvvetli Derecede Önemli & Bir faktör diğerine göre yüksek derecede kuvvetle tercih edilmelidir. \\
\hline $2,4,6,8$ & Mutlak Derecede Önemli & Bir faktör diğerine göre çok yüksek derecede önemlidir. \\
\hline Karşılıklı Değerler & Ara Değerler & íki faktör arasısında küçük farklar olduğunda kullanılır. \\
\hline & \multicolumn{2}{|l}{}
\end{tabular}


İkili karşılaştırma matrisinde wi/wj terimi, amaca ulaşmak için i. kriterin j. Kriterden ne kadar daha önemli olduğunu ifade etmektedir. Bu değerlendirmede Tablo 1'de gösterilen ölçek kullanılmaktadır. Örneğin bu değer 5 ise, i. kriterin j. kritere göre kuvvetli düzeyde önemli olduğu anlaşılmaktadır. Bu durumda benzer şekil j. kriter de i. kritere göre $1 / 5$ düzeyinde önemli olmaktadır.

Kriterlerin göreli önemleri bulunarak matris tutarlılığı hesaplanır. Bir karşılaştırma matrisinin tutarlı olabilmesi için, en büyük özdeğerinin $\left(\lambda_{\max }\right)$ matris boyutuna $(n)$ eşit olması gerekmektedir. Yani $\lambda_{\max }$ kısaca şu şekilde hesaplanır. Karşılaştırma matrisindeki her sütuna ait elemanlar sütunun toplam değerine bölünerek matris normalize edilir. Öncelikler vektörü hesabı için her satırın ortalaması alınır. Daha sonra öncelikler vektörü ile başlangıçtaki karşılaştırma matrisi çarpılarak "Tüm Öncelikler Matrisi" hesaplanır. Elde edilen matris elemanları öncelikler vektörü elemanlarına bölünür. $\lambda_{\max }$ 'ı hesaplayabilmek için bu değerlerin ortalaması bulunur. Bu ortalama bize $\lambda_{\max }{ }^{\prime}$ I verir (Timor, 2011).

$\lambda_{\text {max }}$ ' bulduktan sonra yapmamız gereken işlem tutarlık oranın hesaplanmasıdır. Tutarlık oranını hesaplayarak oluşturulan hiyerarşinin tutarlık derecesini hesaplamış oluruz. Aslında tüm karar verme sürecinin tutarlılı̆ı bu şekilde hesaplanmış olur. Tutarlık oranı dediğimiz bu ölçü karar vericinin ikili karşılaştırmada varsa yaptığı yanlış karşılaştırmayı da saptar. Eğer yanlış bir karşılaştırma varsa uygun bir şekilde değişiklik yapılıp daha sağlıklı karar sonuçları elde edilir. Tutarlık oranı için kabul edilen üst sınır 0,10'dur.Eğer bulunan tutarlık oranı bu değerin üstündeyse yapılan ikili karşılaştırma bir daha gözden geçirilmelidir. Tutarlık oranını hesaplayabilmek için öncelikle tutarlık indeksini(Cl) hesaplamalıyız:

$$
\mathrm{CI}=\left(\lambda_{\max }-\mathrm{n}\right) /(\mathrm{n}-1)
$$

Şeklinde bulunur. CI bulunduktan sonra tutarlık oranı(CR) şu şekilde hesaplanır:

$$
\mathrm{CR}=\mathrm{CI} / \mathrm{RI}
$$

RI rastgele değer indeksini temsil etmektedir. Rastgele değer indeksi tablosundan uygun değer seçilerek işlemler yapılır.

Eğer bulunan tutarlık oranı 0,10'dan küçükse yapılan karar verme işlemi tutarlıdır. Amaca uygun bir şekilde karar uygulanır.

\section{TOPSIS}

TOPSIS (The Technique For Order Preference By Similarity To Ideal Solution ) tekniği ELECTRE yöntemine alternatif olarak Hwang ve Yoon(1980) tarafından oluşturulmuştur. Yöntem alternatiflerin geometrik anlamda pozitif ideal çözüme en az uzaklıkta ve negatif ideal çözüme en fazla uzaklıkta olma esasına dayanır. Yani pozitif ideal çözüme en yakın mesafede olan alternatif aynı zamanda negatif ideal çözüme de en uzak mesafede olan alternatiftir.(Olson, 2004) TOPSIS yönteminde kriter değerleri ve kriter ağırlıkları sayısal değerlerdir. İdeal ya da pozitif ideal çözüm olarak ifade edilen çözüm, fayda kriterini maksimize eden, maliyet kriterini ise minimize eden çözümdür. İdeal çözüm tüm kriterler sağlandıktan sonra tercih edilen alternatiflerin bu kriterleri olması gereken yani ideal seviyelerde yerine getirmesidir. Eğer ideal çözüm uygulanmaz veya ulaşılamaz ise o zaman ideal çözüme en yakın noktanın seçilmesi gerekmektedir(Ghosh, 2011). 
TOPSIS uygulamasında ilk adım olarak karar matrisi oluşturulur. Karar matrisinin satır elemanları olarak üstünlükleri sıralanmak istenen kriterler, sütunlarda ise karar vermede kullanılan değerlendirme faktörleri yer alır. Karar matrisi karar vericiler tarafından oluşturulan başlangıç matrisidir. Aşağıdaki matris $m$ alternatif ve $n$ kriterli bir karar matrisidir.

$$
A=\left[\begin{array}{cccc}
x_{11} & x_{12} & \ldots & x_{1 n} \\
& \vdots & \vdots & \vdots \\
x_{m 1} & x_{m 2} & \ldots & x_{m n}
\end{array}\right]
$$

İkinci adım ise karar matrisinin normalize edilmesidir. Bu adımda farklı ölçeklerdeki değerlendirmelerin aynı ölçeğe getirilerek karşılaştırılabilmeleri normalizasyon işlemi ile olanaklı hale getirilir. Normalleştirme işlemi karar matrisindeki bileşenlerin tüm bileşenlerin kareleri toplamının kareköküne bölünerek yapııı

Üçüncü adım ise ağırlıklı normalize karar matrisinin oluşturulmasıdır.Bu adımda öncelikle değerlendirme faktörlerinin ağırlıkları belirlenir. Ağırlık belirlenirken AHP yönteminden yararlanılır. Ağırlıklar belirlendikten sonra normalleştirilmiş karar matrisinin her bir elemanı $\left(r_{i j}\right)$ ilgili kriterin ağırlığı $\left(w_{\mathrm{j}}\right)$ ile matris gösterimindeki gibi çarpılır.

Dördüncü adım pozitif ve negatif ideal çözümlerin oluşturulmasıdır. TOPSIS yöntemi her değerlendirme faktörünün monoton artan veya azalan bir eğilime sahip olduğunu varsaymaktadır. İdeal çözüme ulaşmak için $\left(A^{*}\right)$ önceki adımda oluşturulan ağırlıklandırılmış normalize matrisin her bir sütunundaki en yüksek ve en düşük değerler seçilir.

$$
\begin{aligned}
& A^{*}=\left\{\left(\max v_{i j} \mid j \in J\right),\left(\operatorname{minv}_{i j} \mid j \in J^{\prime}\right)\right\} i=1,2,3, \ldots, m \\
& A^{-}=\left\{\left(\min _{i j} \mid j \in J\right),\left(\max _{i j} \mid j \in J^{\prime}\right)\right\} i=1,2,3, \ldots, m
\end{aligned}
$$

Burada J fayda kriterini, J' ise maliyet kriterini belirtmektedir. Fayda kriteri için alternatifler arasından maksimum değer, maliyet kriteri için ise alternatifler arasından minimum değer gereklidir. Bu durumda $A^{*}$ en çok tercih edilen alternatifi, $A$ - ise en az tercih edilen alternatifi göstermektedir.

Beşinci adım ise ayırım ölçülerinin hesaplanmasıdır. TOPSıS yönteminde her alternatifin pozitif ideal ve negatif ideal noktalardan sapmasını bulabilmek için Euclidian Uzaklık fonksiyonundan yararlanılır. Bu işlem sonucu elde edilen karar noktalarına ilişkin sapma değerleri ise İdeal Ayırım $\left(S_{i}^{*}\right)$ ve Negatif İdeal Ayırım $\left(S_{i}^{-}\right)$ ölçüsü olarak adlandırılır. Burada hesaplanacak $\left(S_{i}^{*}\right)$ ve $\left(S_{i}^{-}\right)$sayısı alternatif sayısı kadar olacaktır.

$$
\begin{aligned}
& S_{i}^{*}=\sqrt{\sum\left(v_{i j}-v_{j^{*}}\right)^{2}} i=1,2,3, \ldots, m \\
& S_{i}^{-}=\sqrt{\sum\left(v_{i j}-v_{j^{-}}\right)^{2}} i=1,2,3, \ldots, m
\end{aligned}
$$

Altıncı adım ise ideal çözüme göre göreli önceliğin hesaplanmasıdır. Her bir alternatifin ideal çözüme göreli yakınlığının $\left(C_{i}^{*}\right)$ hesaplanmasında ideal ve negatif ideal ayırım ölçülerinden yararlanılır. Burada kullanılan ölçüt negatif ideal ayırım ölçüsünün toplam ayırım ölçüsü içindeki payıdır. İdeal çözüme göreli yakınlık şöyle hesaplanır: 


$$
C_{i}^{*}=\frac{s_{i}^{-}}{S_{i}^{*}+S_{i}^{-}} ; 0 \leq C_{i}^{*} \leq 1
$$

Bu formüle göre negatif ideal çözümden uzaklık değeri arttıkça ideal çözüme yakınlık değeri artmaktadır. Bu durumla ilgili alternatifin İdeal Ayırım değerinin yükselmesi ideal çözüme yakınlığın da azalması anlamına gelir. Aynı şekilde Negatif ayırım değerinin yüksek çıkması ideal çözüme yakınlığın artacağı anlamına gelir.

Son adımda ise her bir alternatif için oluşturulmuş göreli yakınlık değerine bakılarak sıralama işlemi yapılır. Buna göre alternatifler arasında ideal çözüme en kısa uzaklıktaki alternatif yani en büyük $C_{i}^{*}$ değerine sahip olan alternatifin en iyi alternatif olduğu sonucuna varılır. $C_{i}^{*}$ değerlerini büyükten küçüğe sıralayarak alternatiflerin öncelik sıralaması yapılmış olur.

\section{PROMETHEE}

PROMETHEE (Preference Ranking Organization Method For Enrichment Evaluations) yöntemi çok kriterli karar verme tekniklerindendir. Kısmi önceliklendirme imkanı sunan PROMETHEE I ve net önceliklendirme imkanı sunan PROMETHEE II yöntemleri 1982 yılında Jean Pierre Brans tarafından geliştirilmiştir. Aynı yıl ilk defa R. Nadau ve M. Landry tarafından Kanada'da bulunan Laval üniversitesinde sunulmuştur. Birkaç yıl sonra J.P.Brans ve Bertrand Mareschal tarafından aralıklı sıralama yapan PROMETHEE III ve devamlı sıralama yapan PROMETHEE IV metodları geliştirilmiştir.1988'de Brans ve Mareschal PROMETHEE metodunu görsel olarak destekleyen GAIA görsel interaktif sunumunu önermişlerdir.1992 ve 1994 yıllarında ise PROMETHEE V yöntemi ile PROMETHEE VI yöntemleri aynı bilim insanları tarafından geliştirilmiştir. PROMETHEE $\checkmark$ parçalara ayrılmış kısıtları içeren birçok kriterli karar verme yöntemi iken PROMETHEE VI insan beynini simgeler. (Brans and Mareschal,2005)

PROMETHEE yönteminde diğer çok kriterli karar verme yöntemlerinde olduğu gibi birçok birbiriyle çelişen kriter ve bu kriterle uygun olarak en iyi seçimin yapılmak istenen bir alternatif kümesi vardır. Bu seçimi yapabilmek için bir tercih fonksiyonu belirlenmelidir. Temel olarak 6 tane tercih fonksiyonu vardır. Bunlar; olağan, $\mathrm{U}$ tipi, $\mathrm{V}$ tipi, seviyeli, lineer (doğrusal) ve Gaussian fonksiyonlarıdır.

Yöntem 7 adımdan oluşmaktadır. Illk olarak karar vericinin alternatifleri belirlemesi gerekmektedir. Daha sonra alternatiflerin sahip olması gereken kriterler belirlenir ve kriterlerin önem dereceleri tespit edilerek sayısal atamalar yapılır.

Belirlenen alternatifler, kriterler, kriter ağırlıkları ve alternatiflerin ilgili kriterlere göre aldığı değerler bir veri matrisinde tablo haline getirilir. Oluşturulacak veri matrisinde $w=(w 1, w 2, \ldots, w k)$ ağırlıkları , $c=(f 1, f 2, \ldots, f k)$ kriterleri , $A=(a, b, c, \ldots)$ değerlendirilen alternatifleri temsil etmektedir.

Tablo 2. Veri Matrisi

\begin{tabular}{|c|c|c|c|c|c|}
\hline Kriterler & A & B & C & $\ldots$ & $\mathbf{w}$ \\
\hline f1 & f1(a) & f1(b) & $f 1(c)$ & $\ldots$ & w1 \\
\hline $\mathrm{f2}$ & $f 2(a)$ & $f 2(b)$ & $f 2(c)$ & $\ldots$ & $w 2$ \\
\hline$\ldots$ & $\ldots$ & $\ldots$ & $\ldots$ & $\ldots$ & $\ldots$ \\
\hline$\ldots$ & $\ldots$ & $\ldots$ & $\ldots$ & $\ldots$ & $\ldots$ \\
\hline $\mathrm{fk}$ & $\mathrm{fk}(\mathrm{a})$ & $\mathrm{fk}(\mathrm{b})$ & $\mathrm{fk}(\mathrm{c})$ & $\ldots$ & Wk \\
\hline
\end{tabular}


İkinci adımda kriterler için tercih fonksiyonları belirlenir. Yöntemin uygulanmasında 6 farklı tercih fonksiyonu olduğu önceden belirtilmişti.

Üçüncü adımda tercih fonksiyonları dikkate alınarak alternatif çiftleri için ortak tercih fonksiyonları belirlenir. a, b alternatifleri için ortak tercih fonksiyonu şöyledir:

$$
\begin{aligned}
P(a, b)= & \begin{cases}0, & f(a) \leq f(b) \\
p[f(a), f(b)], & f(a)>f(b)\end{cases} \\
& p[f(a), f(b)]=P(x) \\
& P(x)=f(a)-f(b)
\end{aligned}
$$

Dördüncü adımda belirlenen ortak tercih fonksiyonlarından hareketle her alternatif çifti için tercih indeksleri belirlenir. Alternatif kümesinde wi $(i=1,2, \ldots, k)$ ağırlığına sahip k kriter ile değerlendirilen a ve b alternatiflerinin tercih indeksleri şu şekilde hesaplanır:

$$
\pi(a, b)=\frac{\sum_{i=1}^{k} w_{i} x P_{i}(a, b)}{\sum_{i=1}^{k} w_{i}}
$$

Beşinci adımda alternatifler için pozitif $\left(\varphi^{+}\right)$ve negatif $(\varphi-)$ üstünlükler belirlenir. Pozitif ve negatif üstünlük şu şekilde belirlenir:

$$
\begin{aligned}
& \phi^{+}(a)=\sum \pi(a, x) \quad x=(b, c, d, \ldots) \\
& \phi^{-}(a)=\sum \pi(x, a) \quad x=(b, c, d, \ldots)
\end{aligned}
$$

a alternatifi için pozitif ve negatif üstünlük şu şekilde gösterilir:

Altıncı adımda PROMETHEE I ile kısmi öncelikler belirlenir. Kısmi öncelikler alternatiflerin birbirlerine göre tercih edilme durumlarını, birbirinden farksız alternatifleri ve birbirleriyle karşılaştırılamayacak alternatiflerin belirlenmesini sağlar. a ve b gibi herhangi iki alternatifin kısmi öncelikleri şu şekilde belirlenir:

Aşağıdaki koşullardan herhangi biri sağlanıyorsa a alternatifi b alternatifine tercih edilir.

$$
\begin{gathered}
\phi^{+}(a)>\phi^{+}(b) \text { ve } \phi^{-}(a)<\phi^{-}(b) \\
\phi^{+}(a)>\phi^{+}(b) \text { ve } \phi^{-}(a)=\phi^{-}(b) \\
\phi^{+}(a)=\phi^{+}(b) \text { ve } \phi^{-}(a)<\phi^{-}(b)
\end{gathered}
$$

Aşağıdaki koşul sağlanıyorsa a alternatifi b'den farksızdır.

$$
\phi^{+}(a)=\phi^{+}(b) \text { ve } \phi^{-}(a)=\phi^{-}(b)
$$

Aşağıdaki koşullardan herhangi biri sağlanıyorsa a alternatifi b alternatifi ile karşılaştırılamaz

$$
\begin{aligned}
& \phi^{+}(a)>\phi^{+}(b) \text { ve } \phi^{-}(a)>\phi^{-}(b) \\
& \phi^{+}(a)<\phi^{+}(b) \text { ve } \phi^{-}(a)<\phi^{-}(b)
\end{aligned}
$$

Son adımda PROMETHEE II ile alternatiflerin tam öncelikleri hesaplanır. Hesaplanan tam öncelik değerleri ile bütün alternatifler aynı düzlemde değerlendirilerek tam sıralama belirlenmiş olur. 


$$
\phi(a)=\phi^{+}(a)-\phi^{-}(a)
$$

a ve b gibi iki alternatif için hesaplanan tam öncelik değeri hesaplanan tam öncelik değerine bağlı olarak aşağıdaki kararlar alınır:

- $\varphi(a)>\varphi(b)$ ise a alternatifi b'den üstündür.

- $\varphi(a)=\varphi(b)$ ise a b'den farksızdır.

\section{ANA MAKINE SEÇiMi içiN AHP UYGULAMASI}

Ana makine seçimi AHP uygulaması için öncelikle problemin amacı belirlenmiştir. Problemin amacı projeye göre en uygun makineyi seçmektir. Amaç belirlendikten sonra kriterler ve alt kriterler belirlenmiştir. Kriterler belirlenirken konuyla ilgili literatürde yer alan çalışmalar ve satın almada tecrübeli mühendisler dikkate alınmıştır. Belirlenen uygun kriterler, ana kriterler ve alt kriterler olarak sınıflandırılmıştır. Kriterler belirlendikten sonra karşılaştırma yapılacak modellere karar verilmiştir. Modeller seçilen projeye uygun olan modeller arasında yapılmıştır. Buna uygun olarak oluşturulmuş hiyerarşi tablosu Şekil 1'de görülmektedir.

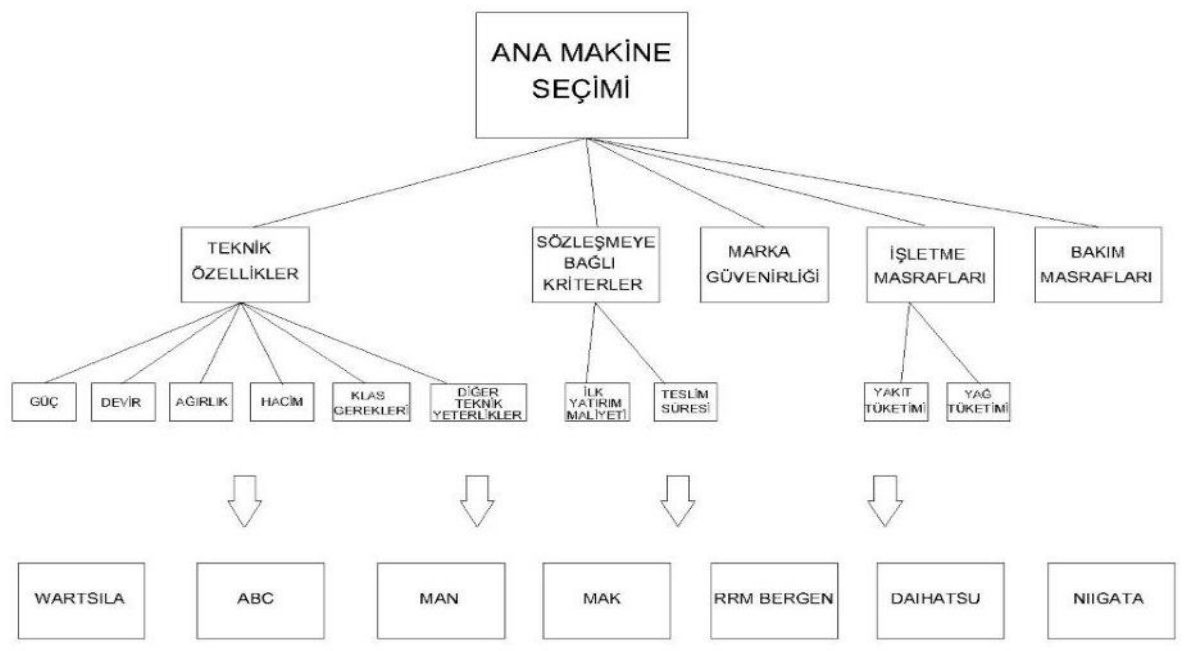

Şekil 1. Karar problemi hiyerarşi tablosu

Hiyerarşi tablosunda problemin amacı ana makine seçimi, ana kriterler; teknik özellikler, sözleşme kriterleri, marka güvenirliği, işletme masrafları ve bakım masraflarıdır. Teknik özelliklere bağlı alt kriterler; güç, devir, ağırlık, hacim, klas gerekleri ve diğer teknik yeterliklerdir. Sözleşmeye bağlı alt kriterler; ilk yatırım maliyeti, teslim süresidir. İşletme masraflarına bağlı alt kriterler; yakıt tüketimi ve yağ tüketimidir. Çalışmada karşılaştırma yapılan makine modelleri Wartsila, ABC, MAN, MAK, RRM Bergen, Daihatsu ve Niigata'dır. Karar hiyerarşisi oluşturulduktan sonra ikili karşılaştırma matrisleri uygulanmıştır. İili karşılaştırma matrisi oluşturulmadan önce ana kriterler ve alt kriterler kendi aralarında önem sırasına dizilmiştir. Ana kriterlerin önem sıralaması şu şekildedir:

- 1- Teknik özellikler

- 2- Sözleşmeye bağlı kriterler

- 3- Marka Güvenirliği 
- 4- İşletme masrafları

- 5-Bakım masrafları

Alt kriterlerin önem sıralaması ise şöyledir:

- Teknik özellikler:

○ 1- Klas gereklilikleri

○ 2-Güç ve devir

○ 3- Ağırlık ve hacim

○ 4- Güç harici istenen teknik yeterlikler

Bu önem sıralamasında güç ve devir farklı kriterler olmasına rağmen ağırlık olarak eşit derecede öneme sahiptir. Aynı durum ağırlık ve hacim kriterleri için de geçerlidir.

- Sözleşme:

- 1- Illk yatırım maliyeti

- 2-Teslim süresi

Ilk yatırım maliyeti kriteri teslim süresi kriterine göre çok kuvvetli derecede önemlidir. Fakat iki kriter olduğu için ikili karşılaştırma matrisi oluşturulamamıştır. Fakat kriterlerin birbirine göre ne kadar önemli olduğunu bilindiği için ağırlıklandırma yapılmıştır. Yani ilk yatırım maliyeti kriteri 7 birim önemli ise teslim süresi 1 birim önemlidir.

- İ̧̧letme masrafları:

○ 1-Yakıt tüketimi

○ 2-Yağ tüketimi

Yakıt tüketimi yağ tüketimine göre çok kuvvetli derecede önemlidir. Sözleşme kriterinin alt kriteri için geçerli olan durum burada da uygulanmıştır.

Bu önem sıralaması sonucu elde edilen ikili karşılaştırma matrisleri oluşturulmuştur

ikili karşılaştırma matrisi oluşturulduktan sonra matris öncelikler vektörüne dönüştürülmüştür. Öncelikler vektörünün bulunması için matris normalize edilir. Normalize edilen matris satırlarının ortalaması alınarak öncelikler vektörü bulunmuş olur.

Tablo 3. Öncelikler ve Tüm Öncelikler Vektörü

\begin{tabular}{|l|l|l|}
\hline Kriterler & Öncelikler Vektörü & Tüm Öncelikler Vektörü \\
\hline Teknik Özellikler & 0,5028 & 2,7431 \\
\hline Sözleşme & 0,2602 & 1,4135 \\
\hline Marka Güvenirliği & 0,1343 & 0,6991 \\
\hline İşletme masrafları & 0,0677 & 0,3409 \\
\hline Bakım Masrafları & 0,0348 & 0,1773 \\
\hline
\end{tabular}

Elde edilen bu vektör ile karşılaştırma matrisinin çarpımı sonucu tüm öncelikler matrisi elde edilir. Tüm öncelikler vektörü elemanları öncelikler vektörü elemanlarına bölünüp 
bu elemanların ortalaması alınır. Bu ortalama sonucu en büyük özdeğer yani $\lambda_{\max }$ bulunmuş olur. $\lambda_{\max }$ 'ı bulma amacı tutarlıık oranını bulmaktır. Tutarlılık oranının 0,1 den küçük çıkması halinde matris tutarlı kabul edilir.

Tutarlık oranını hesaplayabilmek için öncelikle tutarlık indeksini(CI) hesaplamalıyız:

Tutarlık indeksi $=($ 5,24260692-5)/4=0,06065173

şeklinde bulunur. Cl bulunduktan sonra tutarlık oranı(CR) hesaplanır:

Tutarlık oranı $=0,06065173 / 1,12=0,05415333$

Tutarlık oranının 0,1 den küçük çıkması yapılan ikili karşılaştırmanın yani karar vericinin kriterlere ilişkin yargılarının tutarlı olduğunu göstermektedir.

Teknik özellikler kriterinin alt kriterlerinin analizi ise ana kriterlerin değerlendirmesinde kullanılan yolla yapılmıştır.ikili karşılaştırma matrisi oluşturulup daha sonra öncelikler matrisi ve tüm öncelikler matrisi bulunmuştur. Bu hesaplamalardan sonra tutarlık indeksi ve tutarlık oranı bulunmuştur.

Tutarlık indeksi $=(6,14442441-6) / 5=0,028885$

Tutarlık oranı= 0,028885/1,24=0,023294

Tutarlılık oranının 0,1 den küçük çıkması teknik özellikler alt kriterine ilişkin yargıların tutarlı olduğunu göstermektedir.

Sözleşme kriteri iki alt kritere sahiptir. îki kriter olduğu durumda ikili karşılaştırma matrisi oluşturularak bir karşılaştırma yapmak mümkün değildir. Bu durumda karar verici bize kriterlerin birbirine göre durumu hakkında bilgi vermektedir. Sözleşme kriteri ilk yatırım maliyeti ve teslim süresi alt kriterlerinden oluşur. İlk yatırım maliyeti teslim süresine göre çok kuvvetli derecede önemli bir kriterdir. Karar verici burada ilk yatırım maliyeti 7 birim önemliyse teslim süresi 1 birim önemlidir şeklinde yargıda bulunmuştur.

İşletme masrafları kriteri de aynı sözleşme kriterinde olduğu gibi iki alt kriterden oluşmuştur. Bu kriterler yakıt tüketimi ve yağ tüketimidir. Yakıt tüketimi yağ tüketimine göre çok kuvvetli derece önemli bir kriterdir.

Bu kriterler üzerinden alternatiflerin göreli öncelikleri bulunmuştur. Fakat her kriter için bu değerlendirme tek tek yapılmıştır. Bu değerlendirme tercih durumunu etkileme durumuna göre ters normalize veya normalize işlemlerinin yapılması sonucu elde edilmiştir. Öncelikle ana makine için göreli öncelikleri incelenmiştir. Göreli öncelikler gerçek değerler ele alınarak hesaplanmıştır. Teknik özellikler kriterinin alt kriterleriyle değerlendirmeye başlanılmıştır.

Güç kriterinde gerçek değerler üzerinden normalize işlemi yapılmıştır.Çünkü bir makinenin gücü arttıkça tercih edilebilirliği de artar. Bu yüzden güç kriteri karar verme problemine olumlu katkı sağlamaktadır.

Devir kriterinde gerçek değerler üzerinden normalize işlemi yapılmıştır. Devir sayısı arttıkça makinenin tercih edilirliği de artmaktadır.

Ağırlık ve hacim kriterlerinde gerçek değerlerin tersi alınarak normalize işlemi tamamlanmıştır. Çünkü ağırık ve hacim arttıkça makinenin tercih edilirliği azalacaktır. 
Klas gereklilikleri kriterinde herhangi bir işlem yapılmamıştır. Çünkü bütün makineler aynı klasa girdiği için bu kriter ana makinelerin karşılaştırılmasında herhangi bir katkı sağlamamaktadır.

Diğer teknik yeterlilik kriteri; koruma sınıfı, başlama tipi, soğutma tipi, egzoz emisyon derecesi ile ilgilidir. Bu kriterler kendi aralarında eşit öneme sahiptir. Alternatif makinelerin hepsi aynı koruma sınıfı, başlama tipi ve soğutma tipine sahiptir. Bu makineler sıkıştırılmış hava başlama tipinde ve su ile soğutma özelliğindedir.

Sözleşme kriterinin alt kriterlerini ele alalım. Illk yatırım maliyeti kriteri gerçek maliyet değerlerinin tersi alınarak normalize edilmiştir. Maliyet arttıkça tercih edilirlik azalacağı için ters değerler bulunmuştur. Teslim süresi kriterinde 1 değeri verilenler kısa sürede teslim, 2 değeri ise daha uzun sürede teslimi temsil etmektedir. Bu atamalar firmaların imalat yaptıkları yere göre oluşturulmuştur.2 değeri daha uzun süreyi temsil ettiği için ters normalize işlemi yapılmıştır.

Marka güvenirliği kriterinde 1 en güvenilir, 2 güvenilir, 3 daha az güvenilir olmak üzere değer ataması yapılmıştır. Markalar arası bu kıyaslama ise eski projeler ve satın alma biriminde tecrübeli uzman kişiler yardımıyla yapılmıştır. Güvenirlikten kastedilen makinenin zamanında teslimi, uzun süre sorunsuz çalışması, servis ve yedek parça gereksiniminin kısa sürede karşılanmasıdır.Yağ ve yakıt tüketiminde gerçek değerlerin ters normalize değerleri kullanılarak değerlendirme yapılmıştır. Tüketim arttıkça tercih edilirlik azalmaktadır.

Bakım masrafları kriteri yedek parça temini ve servis desteği ile ilgilidir. Firmanın ne kadar yaygın servis ağı varsa tercih edilme oranı o kadar fazladır. 5 en yaygın 1 ise en az yaygın servis ağını belirtmek üzere değerlendirme yapılmıştır. Servis ağı sayısı ise ilgili firmaların web adresleri aracılığıyla temin edilmiştir.

Göreli öncelik vektörleri hesaplandıktan sonra önceden belirlenen ağırlık değerleri ile final tablosu oluşturulmuştur. Final tablosu bulduğumuz ana kriter ve alt kriter ağırlık değerleri ile göreli öncelik vektörlerinden oluşmaktadır. Final tablosunu oluşturduktan sonraki adım karma öncelik vektörünün hesaplanmasıdır. Karar verici karma öncelik değeri en yüksek alternatifi seçer.

Tablo 4. Karar Matrisi

\begin{tabular}{|c|c|c|c|c|c|c|c|c|c|c|c|c|}
\hline $\begin{array}{c}\text { Ana } \\
\text { Kriterler }\end{array}$ & & & Tekı & Özellik & & & Sözleș & & $\begin{array}{l}\text { Marka } \\
\text { Güv. }\end{array}$ & İşletı & Masr. & $\begin{array}{l}\text { Bakım } \\
\text { Masr. }\end{array}$ \\
\hline & Güç & Devir & Ağırlık & Hacim & $\begin{array}{c}\text { Klas } \\
\text { Gerekleri }\end{array}$ & $\begin{array}{c}\text { Diğer } \\
\text { Teknik } \\
\text { Yet }\end{array}$ & $\begin{array}{c}\text { İlk Yatırım } \\
\text { Maliyeti }\end{array}$ & $\begin{array}{l}\text { Tesli } \\
\text { m } \\
\text { Süresi }\end{array}$ & & $\begin{array}{l}\text { Yakıt } \\
\text { Tük. }\end{array}$ & $\begin{array}{l}\text { Yağ } \\
\text { Tük. }\end{array}$ & \\
\hline Kriter No & K1 & $\mathrm{K} 2$ & K3 & K4 & K5 & K6 & K7 & K8 & K9 & K10 & K11 & K12 \\
\hline Ağırlık & 0,096 & 0,096 & 0,040 & 0,040 & 0,210 & 0,018 & 0,227 & 0,032 & 0,134 & 0,059 & 0,008 & 0,034 \\
\hline Wartsila & 4640 & 750 & 46,8 & 5,35 & 5 & 5 & 1000000 & 3 & 1 & 185 & 0,5 & 5 \\
\hline RRM-Bergen & 4500 & 750 & 45,9 & 5,42 & 5 & 5 & 1200000 & 6 & 2 & 185 & 0,8 & 3 \\
\hline MAN & 4500 & 750 & 51 & 9,17 & 5 & 5 & 1000000 & 3 & 1 & 182 & 0,5 & 5 \\
\hline MAK & 4500 & 600 & 49,4 & 8,36 & 5 & 5 & 1100000 & 5 & 1 & 177 & 0,6 & 5 \\
\hline $\mathrm{ABC}$ & 4992 & 720 & 67,7 & 10,3 & 5 & 5 & 800000 & 2 & 2 & 184 & 0,6 & 4 \\
\hline Daihatsu & 4413 & 600 & 67 & 5,86 & 5 & 5 & 625000 & 1 & 2 & 181 & 0,7 & 2 \\
\hline Niigata & 4320 & 720 & 38 & 5,56 & 5 & 5 & 1050000 & 4 & 3 & 183,3 & 0,8 & 1 \\
\hline
\end{tabular}

Karma öncelik değerlerine göre en iyi makine Wartsila, ikinci MAN, üçüncü MAK, dördüncü DAIHATSU, beşinci ABC, altıncı RRM-Bergen, yedinci NIIGATA'dır. 
Tablo 5. Karma Öncelik Değerleri ve Sıralama

\begin{tabular}{|l|c|c|}
\hline Alternatifler & Karma öncelik değeri & Sıralama \\
\hline Wartsila & 0,3521 & 1 \\
\hline RRM-Bergen & 0,3294 & 6 \\
\hline MAN & 0,3483 & 2 \\
\hline MAK & 0,3432 & 3 \\
\hline ABC & 0,3392 & 5 \\
\hline Daihatsu & 0,343 & 4 \\
\hline Niigata & 0,3229 & 7 \\
\hline
\end{tabular}

\section{ANA MAKINE SEÇIMI IÇIN TOPSIS UYGULAMASI}

TOPSIS uygulamasında kriterler ve alternatifler sabit tutularak çözüm işlemi bu yöntemle ele alınmıştır. TOPSis uygulama adımları Excelde formülize edilerek çözümlenmiştir. AHP hiyerarşisinde ele alınan yapı bu yönteme karar matrisi şeklinde uyarlanmıştır. Kriter ve Alt kriterlerin önem dereceleri AHP'de belirlenen önem dereceleridir.

Uygulamanın ilk adımı karar matrisinin oluşturulmasıdır. Buna göre oluşturulan matris AHP yöntemindeki gibi ikili karşılaştırma şeklinde değil puanlama veya değer atama şeklinde oluşturulur. Karar matrisi oluşturulurken her kriter işleme dahil edilmiştir. İkinci adım karar matrisinin normalleştirilmesidir. Bu aşamada her kriterin sütununa ait değerlerin kareleri toplamının karekökleri alınarak normalleşmesi istenen değere bölünmesi ile karar matrisi normalleştirilmiştir. Üçüncü adım ise ağırıklı normalize karar matrisinin oluşturulmasıdır. Bu aşamada normalize karar matrisinin her elemanı ilgili kriterin ağırlığı ile çarpılmış ve ağırlıklı normalize karar matrisi oluşturulmuştu

Dördüncü adım pozitif ve negatif ideal çözümlerin oluşturulmasıdır. Ayırım ölçülerinin hesaplanabilmesi amacıyla her kritere ait en yüksek $\left(A^{*}\right)$ ve en düşük (A-) değerler belirlenmiş ve tüm kriterler için en çok tercih edilen ve en az tercih edilen alternatifler belirlenmiştir. Güç, devir ve bakım masrafları fayda kriteri diğer kriterler ise maliyet kriteri olarak değerlendirilmiştir. Fayda kriterleri için en yüksek değer pozitif ideal, en küçük değer ise negatif ideal çözümdür. Maliyet kriterleri için ise en düşük değer pozitif ideal çözüm, en büyük değer ise negatif ideal çözümdür.

Beşinci adım ayırım ölçülerinin ve ideal çözüme göreli yakınlığın hesaplanmasıdır. Euclidian Uzaklık Yaklaşımına göre her alternatif için tüm değerlendirme kriterlerinin Pozitif ideal ve Negatif İdeal çözüm setinden ayırımları hesaplanmıştır. İkinci sütunda pozitif ayırım, dördüncü sütunda negatif ayırım ölçüsü hesaplanmıştır. Son sütunda ise her alternatifin pozitif ideal çözüme yakınlık değerleri yer almaktadır.

Tablo 6. Ayırım Ölçüleri ve İdeal Çözüme Göreli Yakınlıkları

\begin{tabular}{|c|c|c|c|c|c|}
\hline S1* & 0,0336 & s1- & 0,0616 & C1* & 0,6468 \\
\hline S2* & 0,0601 & $\mathrm{s2-}$ & 0,0316 & $\mathrm{C} 2^{*}$ & 0,3446 \\
\hline 53* & 0,0347 & s3- & 0,0607 & $\mathrm{C}^{*}$ & 0,6358 \\
\hline $54^{*}$ & 0,0449 & 54- & 0,0576 & $\mathrm{C} 4^{*}$ & 0,562 \\
\hline S5* & 0,0344 & S5- & 0,0481 & $\mathrm{C} 5^{*}$ & 0,5829 \\
\hline S6* & 0,0317 & s6- & 0,0603 & C6* & 0,6551 \\
\hline S7* & 0,0685 & s7- & 0,0204 & $\mathrm{C} 7^{*}$ & 0,2299 \\
\hline
\end{tabular}


Son olarak da önem sıralamaları bulunmuştur. İdeal çözüme göreli yakınlığın büyükten küçüğe doğru sıralanması ile en çok tercih edilen alternatifler sıralanmıştır. Yapılan çözümlemeye göre sıralama TOPSIS yöntemine göre önem sıralamasıdır. Buna göre bu proje için seçimi en uygun makine \%65.5 derecelik önemle Daihatsu marka makinedir

Tablo 7.TOPSIS Yöntemine Göre Ana Makine Tercih Sıralaması

\begin{tabular}{|c|l|c|}
\hline Sıralama & Alternatifler & Önem dereceleri \\
\hline $\mathbf{1}$ & Daihatsu & $\% 65,5$ \\
\hline $\mathbf{2}$ & Wartsila & $\% 64,6$ \\
\hline $\mathbf{3}$ & MAN & $\% 63,5$ \\
\hline $\mathbf{4}$ & ABC & $\% 58,2$ \\
\hline $\mathbf{5}$ & MAK & $\% 56,2$ \\
\hline $\mathbf{6}$ & RRM-Bergen & $\% 34,4$ \\
\hline $\mathbf{7}$ & Niigata & $\% 22,9$ \\
\hline
\end{tabular}

\section{ANA MAKINE SEÇIMI IÇiN PROMETHEE UYGULAMASI}

Ilk adım belirlenen alternatifler, kriterler, kriterlerin ağırlıkları ve alternatiflerin ilgili kriterlerle ilgili toplanan verilerinin yer aldığı veri matrisinin oluşturulmasıdır. Fakat bu tabloda tercih durumunu etkilemeyen kriterler işlem kalabalığı oluşturmaması açısından değerlendirilmemiştir. Bu yüzden ağırlıklar ile ilgili bir düzenlemeye gidilmiş ve toplamları 1 olacak şekilde normalize işlemi uygulanmıştır. Bu düzenleme sonrasında PROMETHEE adımları uygulanmıştır.Ikinci aşama kriterler için tercih fonksiyonlarının belirlenmesidir. Marka güvenirliği ve bakım masrafları kriteri dışındaki kriterlerde kullanılan veriler nümerik ve sürekli veriler olduğu için 5 . Tip lineer fonksiyon ile değerlendirme yapılmıştır. Kalan iki kriterde ise kategorik değerler yani kullanılan sayı değerleri gerçek değerleri değil bir anlam ifade ettiği için 1. Tip olağan fonksiyon ile değerlendirme yapılmıştır. Kullanılan fonksiyonlar ve parametreler da verilmiştir. Tercih fonksiyonlarının ve parametrelerin belirlenmesi PROMETHEE programı için kullanılan Visual PROMETHEE ile yapılmıştır.

Tablo 8. Ana Makine Kriter Tercih Fonksiyonları Ve Parametre Tablosu

\begin{tabular}{|l|l|l|l|l|}
\hline \multirow{2}{*}{ Kriter } & Max-Min & Fonksiyon Tipi & \multicolumn{2}{l|}{ Parametreler } \\
\hline Güç & Max & 5. Tip (Lineer) & 432 & 0 \\
\hline Devir & Max & 5. Tip (Lineer) & 137 & 197 \\
\hline Ağırlı & Min & 5. Tip (Lineer) & 21,84 & $\mathbf{8 3}$ \\
\hline Hacim & Min & 5. Tip (Lineer) & 4,1 & 1,7 \\
\hline Ilk Yatırım Maliyeti & Min & 5. Tip (Lineer) & 381546 & 155356 \\
\hline Teslim Süresi & Min & 5. Tip (Lineer) & 3 & 1 \\
\hline Marka Güvenirliği & Min & 1.Tip(Olağan) & - & - \\
\hline Yakıt Tüketimi & Min & 5. Tip (Lineer) & 5,6 & 2,36 \\
\hline Yağ Tüketimi & Min & 5. Tip (Lineer) & 0,25 & 0,1 \\
\hline Bakım Masrafları & Max & 1.Tip(Olağan) & - & - \\
\hline
\end{tabular}

Üçüncü aşamada tercih fonksiyonları dikkate alınarak her kriter için alternatiflerin ikili karşılaş̧ırmaları yapılmış ve ortak tercih fonksiyonları belirlenmiş̧tir. Bu 
değerlendirme yapılırken minimizasyon ve maksimizasyon dikkate alınarak işlem yapılmıştır.Dördüncü aşamada ortak tercih fonksiyonları kullanılarak alternatiflere ilişkin tercih indeksleri belirlenmiştir. Bu değerlendirme Excel yardımıyla yapılmıştır. Beşinci aşamada alternatifler için pozitif $\left(\phi^{+}\right)$ve negatif $(\phi-)$ üstünlük değerleri belirlenmiştir.

Tablo 9. Ana Makine Üstünlük Değerleri

\begin{tabular}{|c|c|c|c|c|c|c|c|}
\hline & Warts & RRM & MAN & MAK & ABC & Dai & Nii \\
\hline $\boldsymbol{\phi}+$ & 0,26 & 0,12 & 0,23 & 0,23 & 0,34 & 0,35 & 0,08 \\
\hline $\boldsymbol{\phi}-$ & 0,1 & 0,32 & 0,12 & 0,24 & 0,2 & 0,29 & 0,35 \\
\hline
\end{tabular}

Altıncı aşamada kısmi sıralama yapılmıştır. Yapılan kısmi sıralamaya göre Wartsila en iyi makinedir. MAN, MAK ve ABC karşılaştırılamaz fakat Daihatsu marka makineye göre daha iyidir. Daihatsu'dan sonra RRM-Bergen, sıralamada en son ise Niigata marka makinedir.Yedinci aşamada ise tam sıralama yapılmıştır. Bu değerler pozitif ve negatif üstünlük değerlerinin farkları alınarak net üstünlük değerlerinin sıralanmasıyla bulunmuştur.

Tablo 10. Ana Makine Tam Sıralama Tablosu

\begin{tabular}{l|c|c|}
\hline Alternatifler & $\Phi$ & Siralama \\
\hline Wartsila & 0,17 & 1 \\
\hline RRM-Bergen & $-0,19$ & 6 \\
\hline MAN & 0,11 & 3 \\
\hline MAK & $-0,01$ & 5 \\
\hline ABC & 0,14 & 2 \\
\hline Daihatsu & 0,06 & 4 \\
\hline Niigata & $-0,27$ & 7 \\
\hline
\end{tabular}

Yapılan tam sıralamaya göre en iyi makine Wartsila, ikinci makine $A B C$,üçüncü makine MAN, dördüncü makine Daihatsu, beşinci makine MAK, altıncı makine RRM-Bergen, yedinci makine ise Niigata'dır. Visual PROMETHEE yardımıyla yapılan tam sıralama da ise en iyi makine Wartsila, ikinci MAN, üçüncü $M A K$, dördüncü $A B C$, beşinci Daihatsu, altıncı ise Niigata'dır. Sıralamaların farklı olma sebebi ise Visual PROMETHEE'nin yuvarlatılmış değerlerle işlem yapması olabilir.

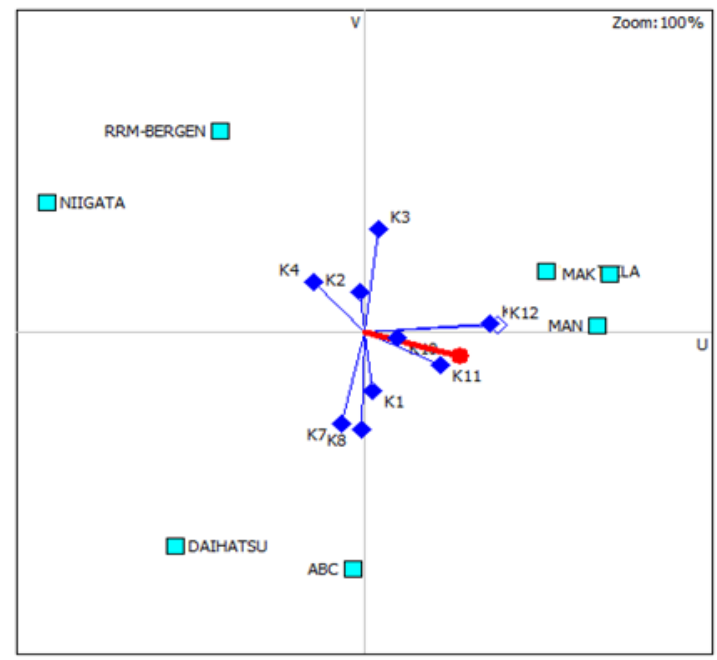

Şekil 2. Visual PROMETHEE GIA Düzlemi çıktısı 


\section{Sonuç ve Öneriler}

Bu çalışmada NB 25 Wartsila dizaynı balıkçı gemisi projesi için uygun ana makine seçimi ele alınmıştır. Bu seçim çok kriterli karar verme yöntemleri olan AHP, TOPSis ve PROMETHEE ile yapılmıştır. Karar probleminin amacı uygun ana makine seçimidir. Bu seçim 12 kritere göre yedi ana makine arasından yapılmıştır. Makinelerin marka ve modeline karar verilmesi projeye uygun veri aralıklarına sahip olması şartıyla sağlanmıştır. Sonraki adımda kriterler oluşturulmuştur. Kriterlere alanında uzman mühendisler ve literatürdeki çalışmalar ışığında karar verilmiş ve bu kriterler önem sıralamasına göre sıralanmıştır. Daha sonra kriterler ikili karşılaştırma matrisleriyle karşılaştırılıp ağırlık değerleri bulunmuştur. AHP yöntemine göre işlem sırası yapılıp karşılaştırma sonuçları elde edilmiştir. TOPSIS ve PROMETHEE yöntemlerinde ilk yöntemde elde edilen ağırlık değerleri kullanılmıştır.

İkinci olarak TOPSIS yöntemi uygulanmıştır. Önce karar matrisi oluşturulup karar matrisi normalleştirilmiştir. Daha sonra ağırlıklı karar matrisi oluşturulup pozitif ve negatif ideal çözümler oluşturulmuştur. Bu adımda kriterlerin maksimum ya da minimum değerlendirilmesine göre ideal çözümler bulunmuştur. Daha sonra ayırım ölçüleri hesaplanıp ideal çözüme göreli yakınlık değerleri bulunmuştur. Sıralama ideal çözüme göreli yakınlık değerlerine göre yapılmıştır.

Son olarak PROMETHEE yöntemi uygulanmıştır. Illk olarak veri matrisi oluşturulmuştur. İkinci adımda her kriter için tercih fonksiyonları belirlenmiştir. Bu adımda Visual PROMETHEE programından yararlanılmıştır. Üçüncü adımda alternatiflerin ikili karşılaştırmaları yapılmış ve ortak tercih fonksiyonları oluşturulmuştur. Dördüncü aşamada tercih indeksleri belirlenip ardından pozitif ve negatif üstünlük değerleri hesaplanmıştır. Pozitif ve negatif üstünlük değerlerine göre kısmi sıralama yapılmıştır.Net üstünlük değerleri bulunarak da tam sıralama yapılmıştır. Bu işlemler hem Excel hem de Visual PROMETHEE ile yapılıp karşılaştırma imkanı elde edilmiştir.

Uygulama sonucu elde edilen veriler şöyledir.

Tablo 11. Ana Makine Seçiminin Farklı Yöntemlere Göre Karşılaştırılması

\begin{tabular}{|l|c|c|c|}
\hline Alternatif & AHP & TOPSIS & PROMETHEE \\
\hline Wartsila & 1 & 2 & 1 \\
\hline RRM-Bergen & 6 & 6 & 6 \\
\hline MAN & 2 & 3 & 2 \\
\hline MAK & 3 & 5 & 3 \\
\hline ABC & 5 & 4 & 4 \\
\hline Daihatsu & 4 & 1 & 5 \\
\hline Niigata & 7 & 7 & 7 \\
\hline
\end{tabular}

Bulunan sıralama sonuçları birbirlerine büyük oranda benzerlik göstermektedir. Wartsila, marka makine AHP ve PROMETHEE yöntemlerinde de ilk sırada, TOPSis yönteminde de ikinci sıradadır. RRM-Bergen marka makine tüm yöntemlerde altıncı sıradadır. MAN marka makine AHP ve PROMETHEE de ikinci sırada TOPSis sonucu üçüncü bulunmuştur. MAK marka makine AHP ve PROMETHEE sonucu üçüncü TOPSiS sonucu beşinci sıradadır. ABC, TOPSIS ve PROMETHEE sonucu dördüncü, AHP sonucu 
beşinci sıradadır. Daihatsu, AHP sonucu dördüncü, TOPSIS sonucu birinci, PROMETHEE sonucu beşinci sıradadır. Niigata ise tüm yöntemler sonucu yedinci sıradadır. Sonuçların birbirine yakın çıkması tutarlı olduğunun ve uygulanabilir olduğunun göstergesidir.

Bu çalışmanın eksik yanları ise şöyle sıralanabilir. Tek proje üzerinde uygulama yapılması araştırmanın en büyük kısıtıdır. Bulunan sonuçlar genel olarak bir bulguya ulaştırmamaktadır. Karşılaştırılan marka ve modeller sadece bir projeye uygun olarak seçilmiştir. Bu yüzden yapılan AHP, TOPSIS ve PROMETHEE sonuçları her zaman benzer benzerlikte çıkmayabilir. Bundan sonraki araştırmacılar bu sorunun üzerinde yoğunlaşabilir. Gelecek zamanlardaki araştırmalarda genel bir sonuç elde edilebilirse sektörde geminin ana damarını oluşturan makine seçimi en verimli şekilde gerçekleştirilmesine katkıda bulunulmuş olur.

\section{KAYNAKÇA}

Brans, J.-P., \& Mareschal, B. (2005). Promethee Methods. J. Figuera, S. Greco, \& M. Ehrgott içinde, Multiple Criteria Decision Analysis:State Of The Art Surveys (s. 163-195). Kluwer Academics. Timor, M. (2011). Analitik Hiyerarşi Prosesi. İstanbul: Türkmen Kitabevi.

Herişçakar, E. (1999). Gemi Ana Makina Seçiminde Çok Kriterli Karar Verme Yöntemleri AHP ve SMART Uygulanması. Gemi İnşaatı Ve Deniz Teknolojisi Teknik Kongresi . İstanbul: Yapım Matbaacılık Ltd.

Kuruüzüm, A., \& Atsan, N. (2001). Analitik Hiyerarşi Yöntemi Ve İşletmecilik Alanındaki Uygulamaları. Akdeniz i.i.i.B.F. Dergisi, s. 83-105.

Macharis, C., Springael, J., Brucker, K. D., \& Verbeke, A. (2004). PROMETHEE and AHP:The Design Of Operational Synergies in Multicriteria Analysis.Strengthening PROMETHEE With ideas of AHP. European Journal Of Operational Research(153), s. 307-317.

Saaty, T. (1994). How To Make A Decision:The Analytic Hierarchy Process. Interfaces, s. 19-43.

Timor, M. (2010). Yöneylem Araştırması. İstanbul: Türkmen Kitabevi.

Olson, D.L. (2004). Comparison Of Weights In TOPSIS Models. Mathematical and Computer Modelling(40), s.721-727.

Ghosh, D.N.(2011). Analytic Hierarchy Process \& TOPSIS Method to Evaluate Faculty Performance in Engineering Education. UNIASCIT(1), s.63-70.

Yaralıoğlu, K. (2001).Performans Değerlendirmede Analitik Hiyerarşi Prosesi. Dokuz Eylül Üniversitesi i.i.B.F. Dergisi, s. 129-142. 